\title{
National Survey of Medication Safety Practice: Environmental Culture and Staff Competency at Primary Healthcare Centers/ Community Pharmacies in Riyadh, Saudi Arabia
}

\author{
Yousef Ahmed Alomi*, (D) The Former \\ General Manager of General Administra- \\ tion of Pharmaceutical Care Former Head, \\ National Clinical Pharmacy and Pharmacy \\ Practice Former Head, Pharmacy R and D \\ Administration Ministry of Health, Riyadh, \\ SAUDI ARABIA. \\ Zainab Abdulmunem Almuallem, Saudi \\ Food and Drug Authority Riyadh, SAUDI \\ ARABIA. \\ Manar Mohammed Alslim, Staff Phar- \\ macist, Prince Sultan Military Medical City \\ Riyadh, SAUDI ARABIA. \\ Rana Mohammed Alslim, Staff Phar- \\ macist Ministry of Health Riyadh, SAUDI \\ ARABIA. \\ Khulud Abdulrahman Alamoudi, \\ Narcotic in-charge, Alhammadi Hospital \\ Riyadh, SAUDI ARABIA. \\ Adel Mehmas Hamdi Alragas, Medical \\ City-king Saud University, Riyadh, SAUDI \\ ARABIA.

\section{Correspondence:} \\ Dr. Yousef Ahmed Alomi, \\ The Former General Manager of General \\ Administration of Pharmaceutical Care \\ Former Head, National Clinical Pharmacy \\ and Pharmacy Practice Former Head, \\ Pharmacy R and D Administration \\ Ministry of Health, Riyadh, SAUDI ARABIA.
}

Phone no: +966504417712

E-mail: yalomi@gmail.com

Received: 17-9-2018;

Accepted: 20-11-2018

Copyright: (c) the author(s),publisher and licensee Pharmacology, Toxicology and Biomedical Reports. This is an open-access article distributed under the terms of the Creative Commons Attribution NonCommercial License, which permits unrestricted non-commercial use, distribution, and reproduction in any medium, provided the original work is properly cited.

This is an open access article distributed under the terms of the Creative Commons Attribution-NonCommercial-ShareAlike 4.0 License

Access this article online

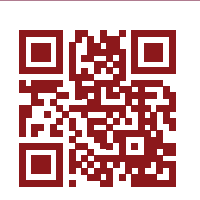

www.ptbreports.org

DOI:

10.5530/PTB.2019.5.5

\begin{abstract}
Objective: To explore the national survey of medication safety practices with an emphasis on environmental factors and staff competencies at primary healthcare centers (PHCs) and community pharmacies (CPs) in Saudi Arabia, Riyadh city. Method: This is a 4-month cross-sectional medication safety practice survey conducted at pharmacies of PHCs of Ministry of Health and CPs in Riyadh city. The survey consisted of the modified version of the Medication Safety Self-Assessment $\circledast$ for Community/ Ambulatory Pharmacy from the Institute of Safe Medication Practices (ISMP). The survey consisted of a demographic section and 10 domains with questions on environmental factors, staff competency and education. The authors distributed the questionnaire and followed-up on a daily basis by physically visiting or via telephonic call. The survey was prepared in an electronic format and it was analyzed through the Survey Monkey system and Microsoft Excel version 10. Result: The survey was distributed to $13 \mathrm{PHCs}$ and $23 \mathrm{CPs}$. The average score of all the ISMP-self assessment of medication safety items at PHCs was $2.75 \pm 0.36(54.94 \%)(95 \%$ confidence interval $(95 \% \mathrm{Cl})=2.55-2.95 ; \mathrm{P}<0.05$; range $=$ 2.04-3.38). The average score of all ISMP-self assessment of medication safety items at CPs was 3.14 $\pm 0.42(62.86 \%)(95 \% \mathrm{Cl}=2.90-4.38 ; P<0.05$; range $=2.40-3.88)$. The average score of environmental factors, workflow and staffing domain at PHCs was $2.7 \pm 0.45(54 \%)(95 \% \mathrm{Cl}=2.53-2.87 ; P<0.05$; range $=1.55-3.68)$, whereas in CPs, the average score was $3.58 \pm 0.43(71.6 \%)(95 \% \mathrm{Cl}=3.44-3.717$; $P<0.05 ;$ range $=2.63-4.37)$. The average score of staff competency and education at PHCs was $3.02 \pm$ $0.298(60.4 \%)(95 \% \mathrm{Cl}=2.9-3.2 ; P<0.05$; range $=2.64-3.55)$, whereas in the $\mathrm{CPs}$, the average score was $4.15 \pm 0.20$ (83\%) $(95 \% \mathrm{Cl}=4.03-4.27 ; P<0.05$; range $=3.78-4.53)$. Conclusion: The PHCs implemented only half of the environmental factors, workflow and staff competency domains preventive measures for medication safety and lower than CPs. Targeting of improving environmental culture and staff competency for medication safety at PHCs is highly recommended in KSA.

Key words: Medication, Safety, Environmental culture, Staff competency, Primary Healthcare centers, Community pharmacy, Riyadh, Saudi Arabia.
\end{abstract}

\section{INTRODUCTION}

Each healthcare facility should follow standard regulations in order to obtain accreditation from the national or international agencies. ${ }^{1,2}$ The engineering department at Ministry of Health $(\mathrm{MOH})$ collaborated with concern professional administration to design the building. Each healthcare professional should have a specific place in the hospital. There has to be a pharmacy at all Primary Care Centers (PHCs). Moreover, the General Administration of Pharmaceutical Care (GAPC) releases the number workforce that should be available per each center and per pharmacy staff competencies. ${ }^{3,4}$ We have previously published a study about patient satisfaction, ${ }^{5}$ in which we analyzed information on patient satisfaction with respect to the location of pharmacy and environmental weather to explore the baseline condition for future improvements. The $\mathrm{MOH}$ released the updated laws and regulations regarding the design, required facilities and the place for pharmacy extemporaneous preparation in CPs.

Similar to other professions, having a good environment will affect the performance level of the employees. In PHCs or Community Pharma- cies (CPs), medications should be prepared and dispensed in a safe and well-organized physical space which allows the pharmacist to remain focused on their work without unnecessary distractions. To enhance safety and work efficiency, it is important to have a well-designed process and workflow at PHCs and CPs. In addition, it is important to have qualified practitioners who can handle the work load without compromising patient safety. To enhance the work efficiency, it is important to know the factors affecting it. These factors include poor lighting, cluttered work space, interruptions, noise, continuous activity, inability of the staff member to remain focused and reduced number of staff members which might increase the work load of the existing pharmacist. However, well-constructed workflow patterns and process can help to reduce chance of error.

Furthermore, staff education is an important error prevention strategy. However, even the most educated, experienced and careful professionals will make errors. Therefore, to overcome errors, it is important to combine error prevention strategies with other strategies. Staff education can 
help in preventing errors when it is focused on priority topics such as new medication being used in the pharmacy; high alert medications; protocols, policies and procedures related to the use of medication and errors occurred in the organization or other organization and its prevention strategy. The surrounding factors and not-so well-competent pharmacist might harm the patient safety. The implementation of medication safety practice with an emphasis on related environmental issues and pharmacy competencies are critical for patient safety. Several publications showed the prevention factors for mistakes should be considered were environmental factors and staff competencies. ${ }^{6-8}$ The Institution of Safe Medication practice (ISMP) releases preventive measures of medication errors with an emphasis on patient competency and environmental culture. ${ }^{9}$ Two studies have been conducted at hospitals in the United States about medication safety in relation to environmental factors and staff competency by using ISMP self-assessment tools. They found that the key element of environmental factors increased from 53 to $64 \%$, whereas the key element of staff competency increased from 48 to $68 \% .^{10,11}$ A local study conducted during Hajj reported that the key elements of the environmental factors and staff competency were 78 and $73.8 \%$, respectively. ${ }^{12}$ All previous investigations have focused on hospital environment and staff competency. However, to the best of our knowledge, there are no studies conducted on the medication safety assessment using ISMP tool at PHCs or CPs. Therefore, in this study, we aimed to explore the national survey of medication safety practices with an emphasis on environmental factors and staff competencies. Thus, it is important to make sure that the ISMP recommendation is being applied in PHCs and CPs in the KSA.

\section{METHODS}

This is a 4-month cross-sectional medication safety practice survey conducted at PHCs and CPs in Riyadh city. The survey has been modified from ISMP Medication Safety Self-Assessment for Community/ Ambulatory Pharmacy. ${ }^{13}$ It consisted of a demographic section and 10 domains with 198 questions. The 10 domains included patient information; drug information; communication of drug orders and other drug information; drug labeling, packaging and nomenclature; use of medical devices; environmental factors; staff competency and education; patient education; quality processes; and risk management domain. The survey was conducted at PHC pharmacies of $\mathrm{MOH}$ and CPs located in Riyadh city. We used 5-point Likert response scale system to obtain responses. The scoring key was identified as number (1) equal to (A): No activity to implement, (2) equal to (B): Considered, but not implemented, (3) equal to (C): Partially implemented in some or all areas, (4) equal to (D): Fully implemented in some areas and (5) equal to (E): Fully implemented throughout. The survey was distributed to the directors of PHCs and CPs. The authors distributed the questionnaire and followed-up on a daily basis by physically visiting and by making a telephonic call. The study questionnaire was prepared in an electronic format and the results were analyzed through the Survey Monkey system and Microsoft Excel version 10. Based on GAPC and Saudi Central Board of Accreditation for Heath Care Institutions (CBAHI) standards, we suggested some solutions to improve the scores of the medication safety practice and the results of the ISMP self-assessment. ${ }^{1,14}$ The 10 domains were divided into several parts for the sake of analysis, discussion and solution. Part one consisted of patient information. Part two consisted of drug information and part three consisted of medication preparation and dispensing (communication of drug orders and other drug information, drug labeling, packaging and nomenclature). Part four consisted of medication administration (drug standardization, storage and distribution, medication devices acquisition, use and monitoring). Part five consisted of environmental factors, workflow, staffing and staff competency and part six consisted of patient education, quality processes and risk management. In this study, we emphasized on part one; it is the finding from medication safety selfassessment for community/ambulatory pharmacy in Riyadh city.

\section{RESULTS}

The survey was distributed to 13 PHCs and 23 CPs. Most of the PHCs were types M1 and M3 (4 (30.8\%) and 3 (23.1\%), respectively). Most of the CPs were large $(8(33.3 \%))$ and medium type $(8(33.3 \%))$. The majority of PHCs and CPs had obtained accreditation from the Saudi Commission of Health Specialties (7 (70\%) and 20 (87\%), respectively). Most of PHCs dispensed more than 100 prescriptions daily (7 (53.9\%)), whereas CPs dispensed less than 20 prescriptions daily (11 (45.8\%)). Most of the responders in PHCs were females (9 (69.2\%)) (4 (30.8\%) were males) and in CPs, all of them were male (25 (100)). The majority of responders in PHCs was Saudi 12 (92.3\%) while non-Saudi 25 (100\%) in the CP. Most of the responders were in the age group of 30-44 years (9 (69.2\%)), whereas those in CP were in the age group of 18-29 (15 (62.5\%)). Most of the responders in PHCs had obtained a diploma or a Bachelor of Science degree in Pharmacy or a Master of Science degree in clinical pharmacy (2 (22.2\%), 3 (33.3\%) and 2 (22.2\%), respectively). Most of the responders in the CP had a Bachelor of Science degree in Pharmacy $(22(88 \%))$. Most of the pharmacy staff had not obtained accreditation from the Board of Pharmaceutical Specialties (8 (88.9\%) and 21 (91.3\%) working in the PHCs and CP, respectively) (Tables 1 and 2). The average score of environmental factors, workflow and staffing domain at PHCs was $2.7 \pm 0.45(54 \%)(95 \% \mathrm{CI}=2.53-2.87$; $P<0.05$; range $=1.55-3.68)$, whereas in the CP was $3.58 \pm 0.43(71.6 \%)(95 \% \mathrm{CI}=$ $3.44-3.717), P<0.05$ and range $=2.63-4.37)$. The average score of staff competency and education at PHCs was $3.02 \pm 0.298(60.4 \%)(95 \% \mathrm{CI}=$ 2.9-3.2; $P<0.05$; range $=2.64-3.55)$, whereas in the $\mathrm{CP}$, it was $4.15 \pm 0.20$ $(83 \%)(95 \% \mathrm{CI}=4.03-4.27 ; P<0.05$; range $=3.78-4.53)$ (Table 3$)$.

At PHCs, the highest score of the environmental factors, workflow and staffing key element with Core \#11 was obtained for the statement "Temperature and humidity are comfortable for workers" (3.64 (72.8\%)), whereas at CPs, the highest score was obtained for the statement "Refrigerators are used only for the storage of medical products and are of sufficient size to allow all drugs to be refrigerated in an organized manner" (4.37 (87.4\%)). The lowest score at PHCs was obtained for the statement "Educational program on stress management has been provided to staff" $(1.82(36.4 \%))$, whereas at CPs, the lowest score was obtained for "All telephone calls to the pharmacy are electronically or manually triaged and forwarded to the dispensing area only when necessary" (3.21 (64.2\%)) (Table 4). The highest score of the environmental factors, workflow and staffing key element with Core \#12 at PHCs was obtained for the statement "Pharmacists are able to maintain a safe balance between time spent in dispensing prescriptions and counseling patients" (3.2 (64\%)), whereas at CPs, it was obtained for "Pharmacy management provides proper balance between operational objectives and pharmaceutical care responsibilities" (3.89 (77.8\%)). The lowest score at PHCs was obtained for the statement "Prescriptions are scanned into the computer or received electronically via a hand-held device or computer" (1.55 $(31 \%)$ ), whereas at CPs, it was obtained for "A magnifying box or lens is in a fixed location and used to facilitate readability of prescriptions and labels" (2.78 (55.6\%)) (Table 5). The highest score of the environmental factors, workflow and staffing key element with Core \#13 was obtained for the statement "Technician and pharmacist staffing takes into account use of supportive dispensing technology and prescription volume and pharmacist/technician ratios are ideally suited to minimize dispensing errors" (3.45 (69\%)) at PHCs, whereas at CP, it was obtained for "Pharmacists have at least $8 \mathrm{hrs}$ of rest between shifts worked. Exception: isolated situations outside of usual operations" (3.94 (78.8\%)). The lowest score at PHCs was obtained for the statement "Pharmacy personnel undergo an annual physical examination, including eye and hearing 
Alomi, et al: National Survey of Medication Safety Practice: Environmental Culture and Staff Competency in KSA

\begin{tabular}{|c|c|c|c|c|}
\hline \multirow[b]{2}{*}{ Region of work } & \multicolumn{2}{|c|}{ Primary care centers } & \multicolumn{2}{|c|}{ Community pharmacies } \\
\hline & Response Count & Response Percent & Response Count & Response Percent \\
\hline $\begin{array}{l}\text { M1: Referral PHCS for post graduate studies } \\
\text { services up to } 32,000 \text { of population. }\end{array}$ & 4 & $30.8 \%$ & Super Pharmacy & $7(29.2 \%)$ \\
\hline $\begin{array}{l}\text { M2: Referral internal sector PHCS services up to } \\
32,000 \text { of population. }\end{array}$ & 0 & $0.0 \%$ & Large Pharmacy & $8(33.3 \%)$ \\
\hline $\begin{array}{l}\text { M3: Referral PHCS services internal cities up to } \\
44,000 \text { of population. }\end{array}$ & 3 & $23.1 \%$ & Medium Pharmacy & $8(33.3 \%)$ \\
\hline $\begin{array}{l}\text { M4: Referral PHCS services internal cities with } \\
\text { housing up to } 32,000 \text { of population }\end{array}$ & 1 & $7.7 \%$ & Small Pharmacy & $1(4.2 \%)$ \\
\hline $\begin{array}{l}\text { M5: Referral external sector PHCS services up to } \\
16,000 \text { of population. }\end{array}$ & 0 & $0.0 \%$ & Other (please specify) & $0(0.0 \%)$ \\
\hline $\begin{array}{l}\text { M6: Referral external sector with housing PHCS } \\
\text { services up to } 16,000 \text { of population. }\end{array}$ & 0 & $0.0 \%$ & Answered question & 24 \\
\hline $\begin{array}{l}\text { M7: Referral small PHCS services up to } 32,000 \text { of } \\
\text { population. }\end{array}$ & 1 & $7.7 \%$ & Skipped question & 1 \\
\hline $\begin{array}{l}\text { A0: primary care centers located at more than } \\
35 \mathrm{Km} \text { distance and services } 2,000-9,000 \text { of } \\
\text { population }\end{array}$ & 2 & $15.4 \%$ & & \\
\hline $\begin{array}{l}\text { B1: Big primary care center located at outside } \\
\text { cities and within, } 35 \mathrm{Km} \text { distance from referral } \\
\text { PHCS, services } 15,000-25,000 \text { of population. }\end{array}$ & 1 & $7.7 \%$ & & \\
\hline $\begin{array}{l}\text { B2: Big primary care center located at outside } \\
\text { cities and within, } 35 \mathrm{Km} \text { distance from referral } \\
\text { PHCS, services } 12,000-15,000 \text { of population. }\end{array}$ & 0 & $0.0 \%$ & & \\
\hline $\begin{array}{l}\text { B3: Big primary care center located at outside } \\
\text { cities and within, } 35 \mathrm{Km} \text { distance from referral } \\
\text { PHCS, services } 3,000-12,000 \text { of population. }\end{array}$ & 0 & $0.0 \%$ & & \\
\hline Other (please specify) & 1 & $7.7 \%$ & & \\
\hline Answered question & 13 & & & \\
\hline Skipped question & 0 & & & \\
\hline \multicolumn{5}{|l|}{ The hospital accreditation } \\
\hline CIBAHI & 1 & $10.0 \%$ & 3 & $13.0 \%$ \\
\hline Joint Commotion USA & 0 & $0.0 \%$ & 0 & $0.0 \%$ \\
\hline Canada & 1 & $10.0 \%$ & 0 & $0.0 \%$ \\
\hline Saudi commission of health accreditation & 7 & $70.0 \%$ & 20 & $87.0 \%$ \\
\hline Non-accredited & 1 & $10.0 \%$ & 0 & $0.0 \%$ \\
\hline Answered question & 10 & & 23 & \\
\hline Skipped question & 3 & & 2 & \\
\hline \multicolumn{5}{|l|}{ Number of prescriptions per day } \\
\hline No more than 20 prescriptions & 0 & $0.0 \%$ & 11 & $45.8 \%$ \\
\hline No more than 30 prescriptions & 0 & $0.0 \%$ & 5 & $20.8 \%$ \\
\hline No more than 50 prescriptions & 1 & $7.7 \%$ & 2 & $8.3 \%$ \\
\hline No more than 70 prescriptions & 1 & $7.7 \%$ & 1 & $4.2 \%$ \\
\hline No more than 100 prescriptions & 3 & $23.1 \%$ & 4 & $16.7 \%$ \\
\hline more than 100 prescriptions & 4 & $30.8 \%$ & 1 & $4.2 \%$ \\
\hline 100-499 prescriptions & 2 & $15.4 \%$ & 0 & $0.0 \%$ \\
\hline 500-999 prescriptions & 0 & $0.0 \%$ & 0 & $0.0 \%$ \\
\hline$=$ or $>1000$ prescriptions & 1 & $7.7 \%$ & 0 & $0.0 \%$ \\
\hline Other (please specify) & 1 & $7.7 \%$ & 0 & $0.0 \%$ \\
\hline Answered question & 13 & & 24 & \\
\hline Skipped question & 0 & & 1 & \\
\hline
\end{tabular}


Alomi, et al.: National Survey of Medication Safety Practice: Environmental Culture and Staff Competency in KSA

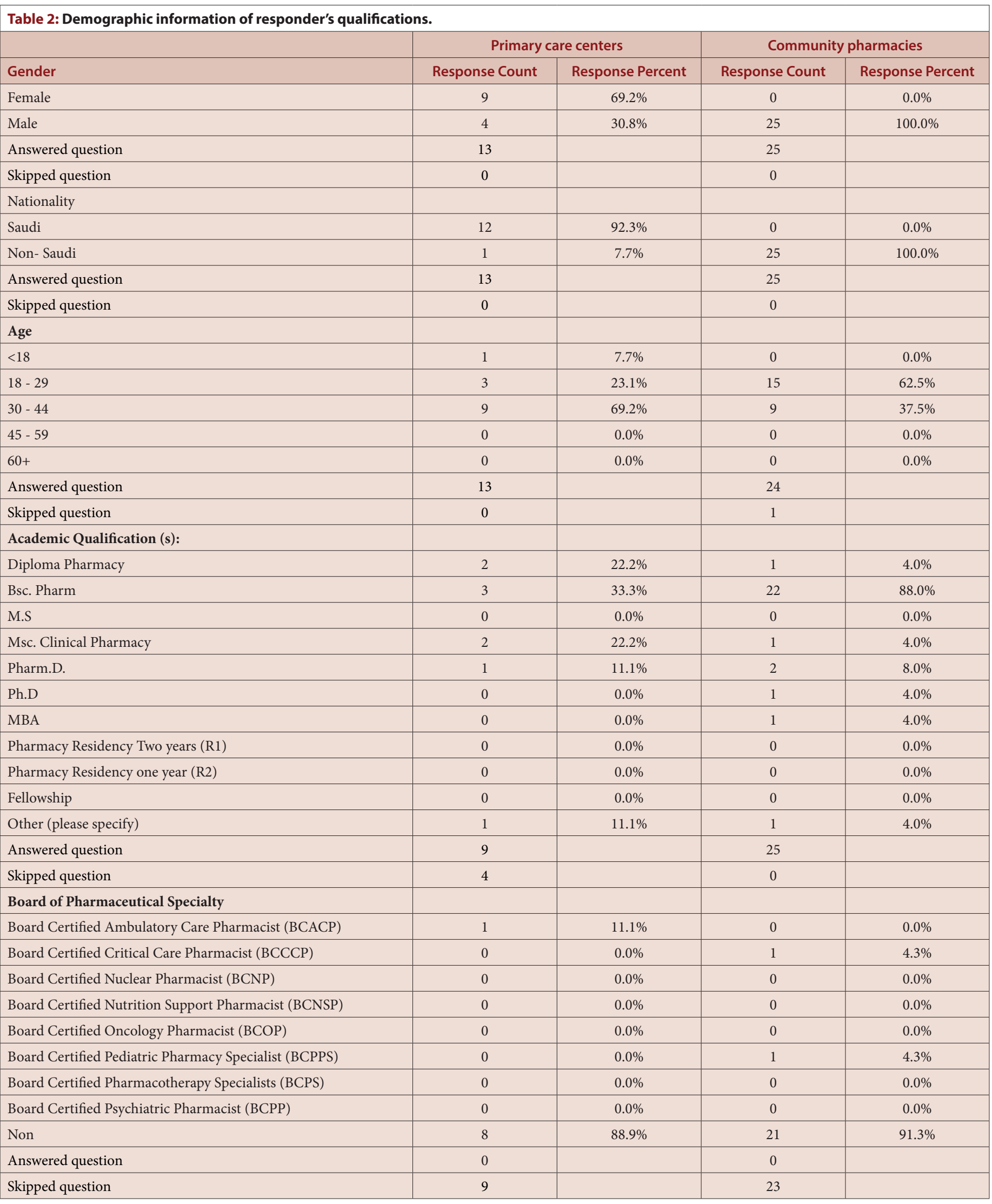




\begin{tabular}{|c|c|c|c|c|c|c|}
\hline \multirow{8}{*}{ 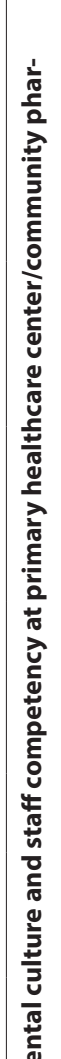 } & 芒号总。 & $\begin{array}{l}0 \\
\infty \\
\infty\end{array}$ & & $\underset{i}{\infty}$ & & \multirow{8}{*}{$\begin{array}{l}\text { screenings" (1.91 (38.2\%)), whereas at CPs, it was obtained for "Sched- } \\
\text { ules and workload permit pharmacists to take at least one } 15 \text {-mins break } \\
\text { and one } 30 \text {-mins break (for a meal) per shift of work each day. Exception: } \\
\text { isolated situations outside of usual operations" ( } 2.63(52.6 \%)) \text { (Table } 6) \text {. } \\
\text { The highest score of the staff competency and education with Core \#14 } \\
\text { at PHCs was obtained for the statement "All new pharmacy staff undergo } \\
\text { a period of supervision, training, observation" ( } 3.55(71 \%)) \text { and at CPs, } \\
\text { it was } 4.39(87.8 \%) \text {. The lowest score at PHCs was obtained for statement } \\
\text { "At least annually, a supervisor evaluates each pharmacy staff member to } \\
\text { assess his/her skills and knowledge related to safe medication practices" } \\
\text { (2.64 (52.8\%)), whereas at CPs, it was obtained for "During orientation, } \\
\text { pharmacists and technicians receive information about the pharmacy's } \\
\text { actual error experiences as well as published errors that may have oc- } \\
\text { curred in other facilities" (4.00 (80\%)) (Table } 7) \text {. The highest score of the } \\
\text { staff competency and education with Core \#15 at PHCs was obtained } \\
\text { for "Pharmacy staff is sufficiently trained on the proper use and mainte- } \\
\text { nance of devices dispensed from the pharmacy" (3.36 (67.2\%)), whereas } \\
\text { at CPs, it was obtained for "Medication errors and ways to avoid them } \\
\text { are routinely discussed at staff meetings and in conversations between } \\
\text { pharmacists, technicians and managers" (4.53 (90.6\%)). The lowest score } \\
\text { at PHCs was obtained for the statement "When errors occur, educational } \\
\text { efforts are widespread among all pharmacy personnel who may make a } \\
\text { similar error, rather than remedial and directed at only those who were } \\
\text { involved in an error" (2.64 (52.8\%)), whereas at CPs, it was obtained for } \\
\text { "Pharmacy management supports educational programs for staff, such } \\
\text { as live continuing education courses, professional meetings, journal club } \\
\text { or in services on new drugs and/or important drug safety issues" (3.78 } \\
\text { (75.6\%)) (Table 8). }\end{array}$} \\
\hline & 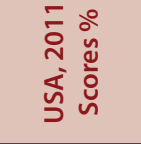 & $\begin{array}{l}8 \\
+ \\
+1\end{array}$ & & $\begin{array}{l}8 \\
\infty \\
\infty \\
0\end{array}$ & & \\
\hline & 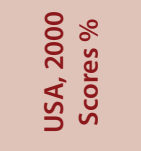 & $\begin{array}{l}8 \\
\text { in }\end{array}$ & & 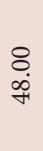 & & \\
\hline & 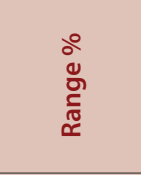 & 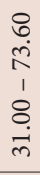 & $\begin{array}{l}\overrightarrow{.} \\
\infty \\
1 \\
\delta \\
0 \\
i \\
\text { in }\end{array}$ & 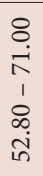 & $\begin{array}{l}0 \\
8 \\
1 \\
0 \\
0 \\
10 \\
1\end{array}$ & \\
\hline & 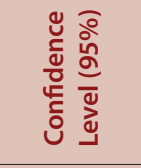 & $\vec{m}$ & $\hat{i}$ & $\stackrel{\sim}{\infty}$ & $\vec{i}$ & \\
\hline & nิ ०० & $a$ & $\infty$ & 2 & $r$ & \\
\hline & 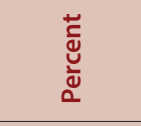 & in & $\vec{K}$ & ठ் & $\infty$ & \\
\hline & $\stackrel{0}{5}$ & in & $\stackrel{\infty}{\infty}$ & $m$ & Fi & \\
\hline
\end{tabular}

\section{DISCUSSION}

The GAPC released the requirement staff for PHCs during the pharmacy strategic plan at the $\mathrm{MOH},{ }^{14,15}$ whereas at the CPs, it depended on the owners. In addition, there are recent regulations from the international pharmacy accreditation agency which recommends the use of enough staff. Therefore, we explored the environmental factors related issues and staff competencies at PHCs and CPs in Saudi Arabia. Our results showed that the environmental factors related to medication safety at CPs were better than those obtained at PHCs. This might be because CP is a bigger space, required staffing and is more organized than that of PHCs. These results are similar to the results of previous international and local studies. ${ }^{10,11,16}$ Moreover, the scores of staff competency at CPs were better than PHCs. In the CPs, especially in the chain pharmacies, although the PHCs had pharmacist competencies, they had a better system of education and training for staff pharmacist. Both of these results are similar to previous international and local studies. ${ }^{10,11,16}$

The lowest score of environmental factors at PHCs was obtained for "Missed the administration skills including the stress management education courses". However, the refrigerators at CPs were not sufficient to store the medications or were not properly organized in the refrigerator. This aspect needs correction at CPs. Core elements of the environmental section (Core \# 12) is related to the usage of computerized facilities and related issues; our results showed that most of them did not use an electronic system for prescribing and dispensing medications. At PHCs, there were problems with regard to the annual examination of staff, whereas at CPs, there was high workload and shortage of breaks during daily work. Both factors may increase stress of staff which may in turn lead to mistakes in the preparation and dispensing of medications. The finding this study with respect to Core \# 14 of staff competency related to safety showed that at PHCs, the evaluation of pharmacy staff is not appropriate to assess their skills and knowledge. This is related to old system of staff evaluation. There is updated information on staff evaluation from Civil Ministry. At CPs, there should be orientation program on 


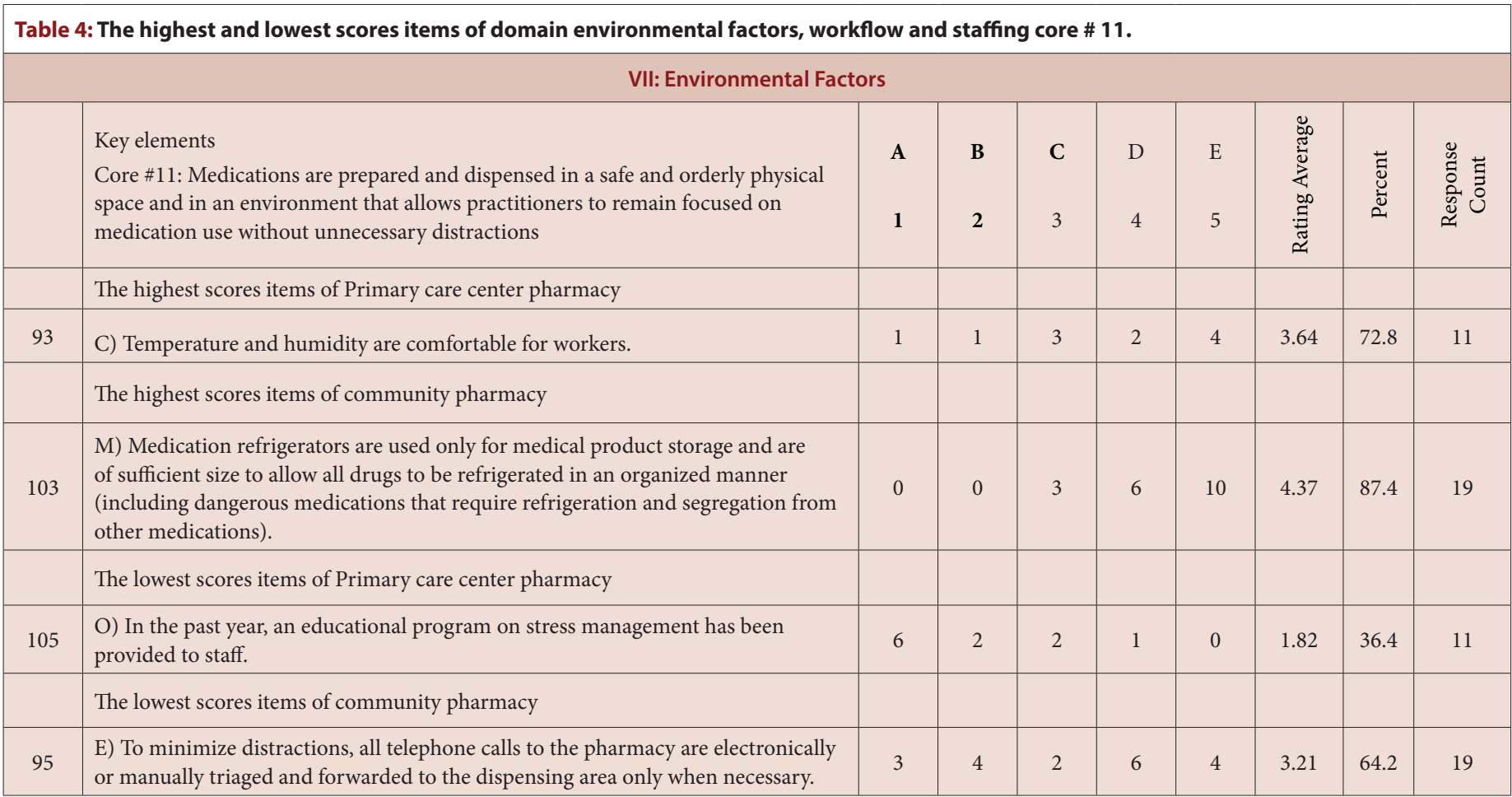

\section{Table 5: The highest and lowest scores items of domain environmental factors, workflow and staffing core \# 12.}

\section{VII: Environmental Factors}

\begin{tabular}{|c|c|c|c|c|c|c|c|c|c|}
\hline & $\begin{array}{l}\text { Key elements } \\
\text { Core \#12: The processes and flow of work have been designed to enhance safety } \\
\text { and worker efficiency. }\end{array}$ & A & B & C & $\mathrm{D}$ & $\mathrm{E}$ & 空 & 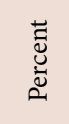 & 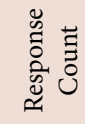 \\
\hline & The highest scores items of Primary care center pharmacy & & & & & & & & \\
\hline \multirow[t]{2}{*}{108} & $\begin{array}{l}\text { R) Pharmacists are able to maintain a safe balance between time spent in } \\
\text { dispensing prescriptions and counseling patients compared to time spent with } \\
\text { claims processors and pharmacy benefits managers in clarifying insurance claims } \\
\text { and formulary coverage issues. }\end{array}$ & 2 & 1 & 2 & 3 & 2 & 3.20 & 64 & 10 \\
\hline & The highest scores items of community pharmacy & & & & & & & & \\
\hline 107 & $\begin{array}{l}\text { Q) Pharmacy management provides proper balance between operational } \\
\text { objectives (e.g., cost-containment, efficiency, productivity, turnaround-time, profit } \\
\text { and loss, etc.) and pharmaceutical care responsibilities. }\end{array}$ & 1 & 2 & 3 & 5 & 8 & 3.89 & 77.8 & 19 \\
\hline 108 & $\begin{array}{l}\text { R) Pharmacists are able to maintain a safe balance between time spent in } \\
\text { dispensing prescriptions and counseling patients compared to time spent with } \\
\text { claims processors and pharmacy benefits managers in clarifying insurance claims } \\
\text { and formulary coverage issues. }\end{array}$ & 0 & 4 & 1 & 6 & 7 & 3.89 & 77.8 & 18 \\
\hline \multirow[t]{2}{*}{109} & $\begin{array}{l}\text { S) Plans for new and/or expanded services are well communicated to all } \\
\text { affected personnel and appropriate consideration of resources is addressed } \\
\text { prior to implementation so that the additional work volume will be met without } \\
\text { compromising patient safety. }\end{array}$ & 0 & 3 & 3 & 5 & 7 & 3.89 & 77.8 & 18 \\
\hline & The lowest scores items of Primary care center pharmacy & & & & & & & & \\
\hline \multirow[t]{2}{*}{$115 \mathrm{~B}$} & $\begin{array}{l}\text { Z) Prescriptions are scanned into the computer or received electronically via a } \\
\text { hand-held device or computer. }\end{array}$ & 8 & 1 & 1 & 1 & 0 & 1.55 & 31 & 11 \\
\hline & The lowest scores items of community pharmacy & & & & & & & & \\
\hline 116 & $\begin{array}{l}\text { AA) A magnifying box or lens is in a fixed location and used to facilitate } \\
\text { readability of prescriptions and labels. }\end{array}$ & 4 & 5 & 3 & 3 & 3 & 2.78 & 55.6 & 18 \\
\hline
\end{tabular}




\begin{tabular}{|c|c|c|c|c|c|c|c|c|c|}
\hline \multicolumn{10}{|c|}{ VII: Environmental Factors } \\
\hline & $\begin{array}{l}\text { Key elements } \\
\text { Core \#13: The complement of qualified, well-rested practitioners and supportive } \\
\text { staff matches the workload without compromising patient safety }\end{array}$ & $\mathbf{A}$ & B & C & $\mathrm{D}$ & $\mathrm{E}$ & 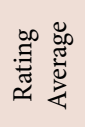 & 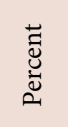 & 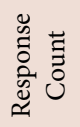 \\
\hline & The highest scores items of Primary care center pharmacy & & & & & & & & \\
\hline \multirow[t]{2}{*}{127} & $\begin{array}{l}\text { MM) Technician and pharmacist staffing (or pharmacy student, intern or resident) } \\
\text { takes into account use of supportive dispensing technology and prescription } \\
\text { volume and pharmacist/technician ratios are ideally suited to minimize dispensing } \\
\text { errors. }\end{array}$ & 2 & 0 & 3 & 3 & 3 & 3.45 & 69 & 11 \\
\hline & The highest scores items of community pharmacy & & & & & & & & \\
\hline \multirow[t]{2}{*}{120} & $\begin{array}{l}\text { EE) Pharmacists have at least } 8 \text { hrs of rest between shifts worked. Exception: } \\
\text { isolated situations outside of usual operations. }\end{array}$ & 2 & 0 & 3 & 5 & 8 & 3.94 & 78.8 & 18 \\
\hline & The lowest scores items of Primary care center pharmacy & & & & & & & & \\
\hline \multirow[t]{2}{*}{117} & $\begin{array}{l}\text { BB) Pharmacy personnel undergo an annual physical examination, including eye } \\
\text { and hearing screenings. }\end{array}$ & 7 & 1 & 1 & 1 & 1 & 1.91 & 38.2 & 11 \\
\hline & The lowest scores items of community pharmacy & & & & & & & & \\
\hline 121 & $\begin{array}{l}\text { FF) Schedules and workload permit pharmacists to take at least one } 15 \text {-mins break } \\
\text { and one } 30 \text {-mins break (for a meal) per shift of work each day. Exception: isolated } \\
\text { situations outside of usual operations. }\end{array}$ & 5 & 4 & 1 & 4 & 2 & 2.63 & 52.6 & 16 \\
\hline
\end{tabular}

\begin{tabular}{|c|c|c|c|c|c|c|c|c|c|}
\hline \multicolumn{10}{|c|}{ VIII: Staff competency and education } \\
\hline & $\begin{array}{l}\text { Key elements } \\
\text { Core \#14: Practitioners and support staff receive sufficient training and } \\
\text { Orientation to the dispensing process and undergo baseline and annual evaluation } \\
\text { of knowledge and skills related to safe medication practices. }\end{array}$ & 1 & 2 & 3 & 4 & 5 & 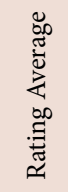 & 节 & 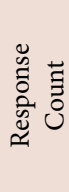 \\
\hline & The highest scores items of Primary care center pharmacy & & & & & & & & \\
\hline \multirow[t]{2}{*}{129} & $\begin{array}{l}\text { A) All new pharmacy staff undergo a period of supervision, training, observation } \\
\text { while performing typical functions and evaluation of skills and knowledge before } \\
\text { participating independently in dispensing activities. }\end{array}$ & 2 & 1 & 1 & 3 & 4 & 3.55 & 71 & 11 \\
\hline & The highest scores items of community pharmacy & & & & & & & & \\
\hline \multirow[t]{2}{*}{129} & $\begin{array}{l}\text { A) All new pharmacy staff undergo a period of supervision, training, observation } \\
\text { while performing typical functions and evaluation of skills and knowledge before } \\
\text { participating independently in dispensing activities. }\end{array}$ & 0 & 1 & 1 & 6 & 10 & 4.39 & 87.8 & 18 \\
\hline & The lowest scores items of Primary care center pharmacy & & & & & & & & \\
\hline \multirow[t]{2}{*}{134} & $\begin{array}{l}\text { F) At least annually, a supervisor evaluates each pharmacy staff member to assess } \\
\text { his/her skills and knowledge related to safe medication practices. }\end{array}$ & 3 & 2 & 3 & 2 & 1 & 2.64 & 52.8 & 11 \\
\hline & The lowest scores items of community pharmacy & & & & & & & & \\
\hline 132 & $\begin{array}{l}\text { D) During orientation, pharmacists and technicians receive information about } \\
\text { the pharmacy's actual error experiences as well as published errors that may have } \\
\text { occurred in other facilities. }\end{array}$ & 0 & 1 & 3 & 9 & 5 & 4.00 & 80 & 18 \\
\hline
\end{tabular}




\begin{tabular}{|c|c|c|c|c|c|c|c|c|c|}
\hline & $\begin{array}{l}\text { Key elements } \\
\text { Core \#15: Practitioners are provided with ongoing education about medication } \\
\text { error prevention and the safe use of drugs and devices that have the greatest } \\
\text { potential to cause harm if misused. }\end{array}$ & 1 & 2 & 3 & $\mathrm{D}$ & $\mathrm{E}$ & 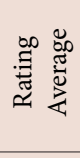 & 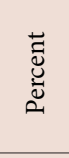 & 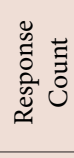 \\
\hline & The highest scores items of Primary care center pharmacy & & & & & & & & \\
\hline \multirow[t]{2}{*}{136} & $\begin{array}{l}\text { H) Pharmacy staff is sufficiently trained on the proper use and maintenance of } \\
\text { devices dispensed from the pharmacy (e.g., glucose monitors, humidifiers, spacers } \\
\text { used with inhalers, etc.). }\end{array}$ & 2 & 2 & 1 & 2 & 4 & 3.36 & 67.2 & 11 \\
\hline & The highest scores items of community pharmacy & & & & & & & & \\
\hline \multirow[t]{2}{*}{138} & $\begin{array}{l}\text { J) Medication errors and ways to avoid them are routinely discussed at staff } \\
\text { meetings and in conversations between pharmacists, technicians and managers. }\end{array}$ & 0 & 0 & 2 & 4 & 11 & 4.53 & 90.6 & 17 \\
\hline & The lowest scores items of Primary care center pharmacy & & & & & & & & \\
\hline \multirow[t]{2}{*}{140} & $\begin{array}{l}\text { L) When errors occur, educational efforts are widespread among all pharmacy } \\
\text { personnel who may make a similar error, rather than remedial and directed at } \\
\text { only those who were involved in an error. }\end{array}$ & 3 & 1 & 5 & 1 & 1 & 2.64 & 52.8 & 11 \\
\hline & The lowest scores items of community pharmacy & & & & & & & & \\
\hline 141 & $\begin{array}{l}\text { M) Pharmacy management supports educational programs for staff, such as live } \\
\text { continuing education courses, professional meetings, journal club or in services } \\
\text { on new drugs and/or important drug safety issues. }\end{array}$ & 0 & 4 & 4 & 2 & 8 & 3.78 & 75.6 & 18 \\
\hline
\end{tabular}

medication safety given to pharmacy staff. The basic medication safety course should be conducted for all CP staff with passing certification. Renewal of medications safety certification should be obtained either annually or once in two years. The pharmacy management of PHCs and CPs should support the medications safety education for pharmacists and pharmacy technicians. The very critical issues related to environmental factors were computerized system-related factors, the workload, medications safety education and training and pharmacy administration support. All these elements should be corrected to prevent medication errors at PHCs and CPs in the KSA.

\section{CONCLUSION}

Self-assessment of medication safety with emphasis on environmental culture and staff competency at PHCs and CPs is the first study in the Middle East countries. The medication safety measures of CPs is acceptable while PHCs need massive improvement. Annual or every two years self-assessment tools is a requirement for all PHCs and CPs in the KSA.

\section{ACKNOWLEDGEMENT}

I want to thank all directors of all primary healthcare pharmacies and community pharmacies for their cooperation and filled the survey.

\section{CONFLICT OF INTEREST}

None

\section{ABBREVIATIONS}

PHCs: Primary healthcare centers; CPs: Community pharmacies; CBAHI: Saudi Central Board of Accreditation for Heath Care Institutions; GAPC: General administration of pharmaceutical care; ISMP: Institute of Safe Medication Practice; MOH: Ministry of Health; KSA: Kingdom of Saudi Arabia; USA: United States of America.

\section{ORCID ID}

Yousef Ahmed Alomi iD https://orcid.org/0000-0003-1381-628X

\section{REFERENCES}

1. Medication Management (MM). In: National Hospital Standards. $2^{\text {nd }}$ Edition. Saudi Central Board for Accreditation of Healthcare Institutions. 2015;194-211.

2. The Joint Commission. Comprehensive Accreditation Manuals. Joint Commission Resources. 2016.

3. Alomi YA. Primary Care Center Pharmacy Manpower New Guidelines in Saudi Arabia. J Pharmacol Clin Res. 2016;1(1).

4. Alomi YA. National Primary Care Pharmacist Competency System at $\mathrm{MOH}$ in Saudi Arabia. J Pharm Pharm Sci. 2017;1(14):1-5

5. Alomi YA. Patient satisfaction of pharmaceutical care system at Ministry of Health in Saudi Arabia. BAOJ Pharm Sci. 2016;2(1).

6. Barber N, Rawlins M, Franklin BD. Reducing prescribing error: competence, control and culture. Qual Saf Heal Care. 2003;12(suppl 1):i29-32.

7. Alsulami Z, Conroy S, Choonara I. Medication errors in the Middle East countries: A systematic review of the literature. Eur J Clin Pharmacol. 2013;69(4):9951008.

8. American Society of Hospital Pharmacists. ASHP guidelines on preventing medication errors in hospitals. Am J Hosp Pharm. 2018;75:1493-517.

9. Institute for Safe Medication Practices. ISMP Medication Safety Self Assessment for Hospitals. 2011;1-4. Available from: http://ismp.org/selfassessments/ Hospital/2011/definitions.pdf

10. Smetzer JL, Vaida AJ, Cohen MR, Tranum D, Pittman MA, Armstrong CW. Findings from the ISMP Medication Safety Self-Assessment for hospitals. Jt Comm J Qual Saf. 2003;29(11):586-97.

11. Vaida AJ, Smetzer JL, Lamis RL, Cohen MR, Kenward K. Assessing the state of safe medication practices using the ISMP medication safety self assessment $\circledast$ for hospitals: 2000 and 2011. Jt Comm J Qual Patient Saf. 2014;40(2):51-67.

12. Alomi YA, Khayat NAY, Baljoon MJ, Bamagaus YA, Jumah HMA. National Survey of Hospital Medication Safety Practice during Mass Gathering (Haji-2016) in Makkah, Saudi Arabia: Environmental Culture and Staff Competency. J Pharm Pract Community Med. 2017;3(4s):s15-21. Available from: http://jppcm.org/article/113

13. Michael R. Cohen. Medication Safety Self Assessment ${ }^{\mathrm{TM}}$ for Community/Ambulatory Pharmacy. 2001.

14. Alomi YA, Alghamdi SJ, Alattyh RA. Strategic Plan of General Administration of Pharmaceutical Care at Ministry of Health in Saudi Arabia 2012 - 2022. JPharm Pharm Scien. 2015;1(13):1-8.

15. Ahmed Alomi Y. National Primary Care Pharmacist Competency System at MOH in Saudi Arabia. J Pharma Pharm Sci. 2016;1(4):1-5.

16. Alomi YA, Khayat NAY, Baljoon MJ, Bamagaus YA, Jumah HMA. National Survey of Hospital Medication Safety Practice during Mass Gathering (Hajj-2016) in Makka, Saudi Arabia: Medication Administration. J Pharm Pract Community Med. 2017; 3(4s):s36-s42 